\title{
A FORMAÇÃO INICIAL E CONTINUADA DOS PROFESSORES DE ADOLESCENTES: OS ADOLESCENTES EXISTEM?
}

\section{Initial and Life-Long Education of Teachers for Adolescents: Do Adolescents Exist?}

Resumo

\author{
Analise de Jesus da Silva ${ }^{1}$
}

Esse texto tem porobjetivo apresentarconsiderações tecidas em nossa pesquisa de Mestrado $^{2}$ discutindo as relações entre formadores, professores e adolescentes da formação inicial à prática na Educação Básica. A primeira consideração que se destaca é a quase inexistência da abordagem das vivências dos adolescentes nas práticas dos formadores. A ausência de conteúdos que discutam esse momento do desenvolvimento humano revela uma negação da importância do estudo de suas vivências específicas. A segunda delas é a forte identificação entre a concepção de educação adotada pelos formadores e suas manifestações na prática pedagógica deles. As manifestações que aparecerem, aqui, são a relação que os formadores estabelecem com os licenciandos, a concepção que os formadores têm de formação de professores, o grau de inserção dos formadores no processo da Educação Superior. Esão, em grande medida, resultantes da concepção educacional adotada pelos formadores, da não exigência de formação didática e/ou de vivências com aquelas etapas educacionais pelos formadores, pela inexistência de uma política de formação continuada e até mesmo de espaços pedagógicos e físicos que facilitem as práticas coletivas dos formadores. Constatamos escassez de bibliografia concemente a adolescentes, adolescentes pobres, formação inicial e continuada de formadores da Educação Superior, como, também, de bibliografia que trate da relação entre estes temas e entre os sujeitos envolvidos neles.

Palavra-chave: Fomação de professores; Adolescentes.

1 Mestre em Educação pela FaE/UFMG, Professora do Programa de Pós-Graduação Especialização Lato Sensu em Docência na Educação Básica para Professores da Rede Municipal de Educação de Belo Horizonte/FaE/UFMG, Doutoranda em Educação pela FaE/UFMG, Professora da Rede Municipal de Educação de Belo Horizonte, Coordenadora Estadual da Ação Conexões de Saberes+Escola Aberta na UFMG. esilana@gmail.com

Master in Education from FAE/UFMG, Lecturer at the Post Graduation Lato Sensu Specialization Program in Basic Education Teacher's Training for Teachers from Belo Horizonte Municipal Schools/FAE/UFMG; Ph.D. studentatFAE/UFMG; Teacher at one of Belo Horizonte Municipal Schools; State Coordinator of the Program Knowledge Connections + Open School.

2 Em 2002, concluímos a pesquisa de Mestrado intitulada Relações entre formadores, professores eadolescentes: de objetos no labirinto a sujeitos da educação, pormeio da qual objetivávamos investigar a existência ou não da abordagem dos sujeitos adolescentes durante o licenciamento de seus professores durante a graduação. In 2002, we finished our Master's research project entitled "Relationships between teacher's trainers, teachers and teenager students: from objects in the Maze to Subjects in Education, in which we tried to investigate the existence or not of the study of adolescents as subjects during teacher's education in graduate programs. 


\section{Abstract}

This textaims to presentconsiderations previously introduced by ourselves in our Master's research, which broughtup the relationships between teacher's trainers, teachers and teenager students, from the initial teacher's professional schooling to the practice at Basic Education. The first consideration emphasizes the almost non-existence of teenagers life approach in the expenience of teacher's trainers. The absence of curricular subjects that discuss this stage of human development brings about a denial of the importance of the study of their specific life experiences. The second consideration is the strong identification of the education conception adopted by teacher's trainers with its manifestation in their pedagogical practice. Such manifestations, here, are the relationship that trainers establish with their graduate students, the conceptions held by trainers about teacher's schooling, the degree of insertion of trainers at third level education. And they are, to a great extent, resulting from the educational conception adopted by trainers, from the non-requirement of didactic schooling and/ or of practices at those educational stages by the trainers, from the non-existence of a life-long schooling policy and even from the pedagogical and physical spaces thatfacilitate group practices of trainers. We acknowledged lack of bibliography conceming adolescents, poor adolescents, initial and life-long education of trainers of third level education as well as bibliography dealing with the relationship between these subjects and the subject people involved with them.

Keywords: Initial education of teachers; Adolescents.

\section{Introdução}

O desejo de realizar uma pesquisa que estudasse uma das possíveis razões que explicassem as dificuldades manifestadas por professores no trato com estudantes adolescentes nasceu de vivências que presenciamos com freqüência na Sala dos Professores. Citamos, aqui, algumas delas, aquelas que desenvolvemos neste estudo. Há uma lacuna na formação inicial dos professores? Caso haja, ela é intencional? Nesse caso, a intencionalidade é política, pedagógica ou político-pedagógica? Que concepção educacional norteia a prática dos formadores? Qual é a concepção de formação de professores dos formadores? Há diálogo na ES com relação às teorias do conhecimento e às concepções educacionais? Que metodologias e práticas se desenvolvem nas Licenciaturas? Os formadores trabalham com alguma noção de adolescência? Qual? De onde ela provém? Como a formação dos formadores é pensada? A formação pensada se articula com as demandas da formação de professores? E com os estudantes com os quais os licenciados partilharão conhecimentos? Os formadores são sujeitos no processo de constituição das Licenciaturas? Ocorre o diálogo entre os formadores na Educação Superior - ES? Há uma articulação entre as diferen- 
tes disciplinas no sentido de dar identidade aos currículos dos cursos de graduação? Pautado em que concepção de formação de professores se constroem os currículos das Licenciaturas? Os formadores concebem-se educadores? Ante o cenário da educação em âmbito mundial, as Licenciaturas estão discutindo o redimensionamento da ação educativa? Questões como cidadania, musicalidade, artes, sexualidade, abuso de drogas, violência, economia, desemprego, adolescência, diversidade, raça, gênero, classe social, etc. dialogam com o objeto específico na formação docente nos currículos e nas práticas das Licenciaturas? As posturas dos formadores repercutem nas posturas da prática pedagógica dos professores no EF e no EM? Os formadores reproduzem ou propõem?

Reiteramos, em definitivo, que a intenção de buscar certezas ou rótulos para classificar os sujeitos docentes universitários inexistiu neste trabalho.

\section{0 caminho que fizemos ao caminhar}

O desvelamento dessas questões ocorreu durante entrevistas, observações de aulas, análise documental, conversas informais, movimentos próprios dos pensamentos, e, assim, desenharam-se similaridades e constâncias nas práticas e nas concepções dos formadores que exploramos, dentro dos nossos limites, apesar da amplitude que os contatos com os entrevistados nos proporcionaram.

Este artigo tem por objetivo relatar pesquisa de Mestrado que se propôs investigar a (in)existência da abordagem de vivências adolescentes na formação inicial de professores, focalizando a prática dos formadores universitários, na Licenciatura, e os fatores que influenciam nessa existência ou inexistência. É importante entender que esta formação inicial visa o exercício do magistério no Ensino Fundamental e no Ensino Médio, compreendendo, portanto, estudantes adolescentes. Numa abordagem de pesquisa qualitativa, foram entrevistados 32 formadores de 24 professores de 16 estudantes adolescentes ${ }^{3}$. Os formadores são 8 de cada uma das unidades administrativas selecionadas. Os professores e os estudantes são vinculados a escolas municipais em Belo Horizonte.

3 Na seleção dos sujeitos da pesquisa constituiu critério de escolha ter sido formador de professores que estivessem em serviço com estudantes adolescentes. Desta forma, todos os 32 formadores lecionaram para algum dos 24 professores e estes, por sua vez, lecionavam para algum dos 16 estudantes adolescentes. 


\section{0 que é licenciar?}

As questões a serem debatidas para orientar a aprendizagem, construir o licenciamento, direcionar a formação de professores são inúmeras e históricas.

Destacamos, em primeiro lugar, que o caráter de modalidade que a Licenciatura ocupa comumente nos cursos de graduação é marcadamente diferenciado do caráter de centralidade ocupado pelo Bacharelado (Anexo 1). O Bacharelado surge como percurso natural que carrega como apêndice a Licenciatura. Essa é caracterizada como modalidade de menor importância, inclusive por grande maioria dos próprios formadores ${ }^{4}$.

Acrescentamos a essas afirmações ou como resultado delas a inexistência de um projeto institucional que trabalhe as especificidades das diferentes etapas da Educação Básica quanto aos diferentes momentos do desenvolvimento humano dos sujeitos neles envolvidos com suas vivências e socializações específicas e de conjunto.

Por último, a organização institucional que determina a organização curricular nas Licenciaturas faz delas anexos dos Bacharelados e isso inviabiliza a construção de um currículo que se caracterize pela existência de uma identidade própria.

Quanto à discussão do (re)direcionamento dos cursos, feita a opção pela modalidade, esse movimento deve perpassar todo o curso que, ao se propor formador, licenciador de professores, assumirá essa função na íntegra. Essa função será revelada no momento da concepção do curso. Um curso que se esboce como alternativa na construção de práticas educacionais desejáveis não se estruturará com uma parte teórica e uma outra parte pedagógica, pois trabalhará com a concepção que entende o processo educacional como um todo. Os licenciados estariam, então, habilitados a lecionar História, Matemática e Ciências Biológicas para estudantes adolescentes do Ensino Fundamental (EF) e do Ensino Médio (EM). Entretanto, tal prática demanda uma concepção de educação e uma postura profissional segundo as quais os formadores de professores se posicionem como sujeitos na formação profissional de outros sujeitos.

\section{Formador e educador}

Consideramos, portanto, que as atividades do formador exigem constante reflexão sobre sua prática educacional, sobre seu papel na modalidade

4 Quando nos referimos aos formadores, falamos de professores da Educação Superior e, quando nos referimos a professores, falamos de professores da Educação Básica. 
Licenciatura, sobre sua atuação como sujeito na construção do currículo que embasará a condução de suas aulas. Tal reflexão se dará coletivamente uma vez que os licenciandos são estudantes do Curso e não de cada formador. Nesse sentido, queremos assinalar que, mesmo não tendo sido possível detectar tentativas substanciosas em termos de reflexão e trabalho coletivo para minorar a situação do curso, foi recorrente o número de vezes em que ouvimos dos formadores entrevistados a avaliação de que as Licenciaturas nas quais trabalham não têm estrutura, desenvolvimento, nem resultado satisfatórios.

Nessa perspectiva, na formação inicial, na modalidade Licenciatura, não há espaço para os futuros professores refletirem sobre como ser professores, de História da Revolução Francesa, de Equações Incompletas do $2^{0}$ Grau, de Ecossistemas Brasileiros e de outros tantos conhecimentos científicos historicamente acumulados, para adolescentes. E isso ocorre, mesmo sendo licenciados para a prática do magistério no $\mathrm{EF}$ e no EM, que são etapas da educação brasileira, sendo a primeira de freqüência obrigatória, de acordo com a Lei 9394/98, Lei de Diretrizes e Bases da Educação Nacional - LDB, para cidadãos e cidadãs com idades entre os $11 / 12$ e os $17 / 18$ anos de idade, cidadãos esses caracterizados como adolescentes de acordo com a Lei 8.069, de 13/07/1990 Estatuto da Criança e do Adolescente - ECA.

Sobre o levantamento do perfil dos entrevistados, os dados demonstraram que $41 \%$ dos sujeitos formadores de professores não cursaram a modalidade Licenciatura. Dos 59\% que o fizeram, 58\% nunca deu aula para os quatro últimos anos do $\mathrm{EF}$ e $79 \%$ nunca deu aula para o EM. A fala de um professor da Licenciatura reafirma esta leitura:

E é uma disciplina que procurava, exatamente, fazer essa ligação da formação do sujeito com a escola, com a prática que ele ia ter[...] Mas os cursos de Licenciatura eram e ainda continuam, continuam ainda com essa crítica: totalmente desvinculado da prática do estudante. Da prática social. Dessa prática que eu considero que é o fundamental. Por que, por exemplo, eu vou te falar da [...] que eu considero que é o mais avançado. A licenciatura na [...] é a mais avançada, entretanto, existe um paradoxo nisso aí. Eu fiz essa pesquisa, por isso que eu vou te afirmar o que eu tô te falando agora: todos, não tô te falando exceto, não. Tô te falando todos. Todos os professores que davam aula na ...na época que eu trabalhei na ...todos os professores que davam aula na Licenciatura, eles eram bacharéis. Não eram licenciados. Sabe como é que foi a história deles? Eles terminaram o Bacharelado, fizeram concurso, entraram pra Universidade e eles nunca puseram o pé, o dedinho do pé, numa escola de 5. a a 8. ${ }^{a}$ série ou de Ensino Médio, ou seja, Ensino Fundamental e Médio. Nunca puseram o pé. Ora, se eles não têm essa prática, como é que eles vão dar aula pra Licenciatura? Então, essa contradição, ela é grande na ...ainda que a ...tente avançar. Mas ela vai ficando maior ainda, 
mais ampla ainda na [...], na [...] Aqui na [...]tá chegando uma leva muito interessante de colegas .É o pessoal que terminou uma graduação, às vezes, na ..., na .... Sei lá onde! E nunca pôs o pé numa sala de 5.a a $8 .{ }^{\text {a }}$ série. Que nunca pôs o pé numa sala de $2 . \stackrel{0}{ }$ grau, que dirá de $1 . \stackrel{\mathrm{a}}{\mathrm{a}} \mathrm{a} 4 . \stackrel{\mathrm{a}}{\mathrm{a}}$, isso aí nem entra. Então é um povo que nunca pôs o pé. Fez o mestrado, fez um concurso, entrou aqui como professor assistente, tão indo pro doutorado e vão formar o professor que vai trabalhar de 5. a a 8. ${ }^{\text {a }}$ e no Ensino Médio [risos]. Não tem jeito, né?É um paradoxo, é uma contradição violenta. Eé toda uma política dentro da Universidade, é toda uma questão de valorização dos bacharelados, em detrimento das licenciaturas, né, que é uma questão violenta. Izanagi.

Aqui, consideramos importante abrir um parêntese para localizar uma questão relevante quanto à forma como identificamos cada sujeito após seus comentários. Nossa intervenção como pesquisadora no contexto observado foi mínima. Procuramos descrever, com riqueza de detalhes, as situações e transcrever, literalmente, as falas para, então, poder, inclusive, apreender a importância atribuída pelos participantes diretos - os formadores - e os indiretos - os professores e os adolescentes - ao fenômeno estudado. Quanto à identificação desses sujeitos, as mais diversas partes do mundo, desde a Mesopotâmia, Egito, América do Sul, Eslovênia, Grécia, Roma, América do Norte, Irlanda, Oceania, África, Brasil, entre outros, foram lugares onde buscamos na mitologia os nomes para substituir os verdadeiros nomes dos entrevistados. E por que na mitologia?

O conhecimento histórico diz que, desde sempre, os seres humanos transmitiram às gerações seguintes seus mitos. Por toda parte, desde os esquimós aos povos do mais extremo sul, por meio das narrativas, dos desenhos, dos templos, dos escritos entre outras manifestações, as peripécias de heróis, protegidos ou atacados por deuses e esses com origem nas divindades primevas, são relatadas. Optei, então, por nomear os formadores como deuses primeiros, aqueles a quem se atribui a origem de tudo, os professores como deuses originados daqueles, mas também divindades e os adolescentes como heróis, portanto, apesar de descendentes ou de protegidos pelos deuses, sendo humanos. Segundo Wilkinson (2000:09),

Quase sempre o ser humano aparece relativamente tarde no processo de criação. Pode-se dizer que a chegada da humanidade é uma idéia posterior, que chega depois do trabalho bem mais importante de criar o cosmo e as divindades. A criação dos humanos em geral é um ato deliberado de deuses e deusas, que pode ser descrito por meio de alguma atividade humana familiar. 


\section{Habilitado a trabalhar com quem?}

Encerramos esse parêntese retornando à análise anterior. Quando o professor de EF e EM pensa o adolescente, reproduz o formador, que, por sua vez, reproduz nosso modelo social e que pensa o adolescente não como sujeito, mas como objeto, não como adolescente, mas como estudante. Enfim, como tábua rasa na qual o professor deverá imprimir os conhecimentos, moldando seu comportamento por meio de estímulos externos. A concepção de adolescência que aí se verifica é a de uma passagem e desconsidera suas vivências específicas, seus saberes anteriores e, em virtude disso, nas relações escolares, esses estudantes são negados enquanto sujeitos de seus processos. Tal concepção anula a possibilidade de perceber os adolescentes não como uma unidade, mas como diversidade, com especificidades definidas por seus pertencimentos de gênero, raça, classe social, religião, tribo, localização histórico-geográfica, de história de vida. Tais características vão além das características comuns à representação social que se constrói deles.

Segundo Melucci (1997:08), a adolescência é a fase inicial da juventude. Sendo assim, essa seria então a fase desse momento do desenvolvimento humano na qual o tempo começa a ser encarado como uma dimensão significativa e contraditória da identidade do sujeito. É ainda esse autor quem afirma que "não há dúvida que, se a experiência do envelhecimento está sempre relacionada com o tempo, é durante a adolescência que essa relação se torna consciente e assume conotações emocionais".

A priorização das juventudes, entendidas como momento do desenvolvimento humano, desvelando o modo como cada sociedade vê esse momento, isto é, a condição juvenil, pautada nos sujeitos concretos deste momento, os jovens e as jovens e os diferentes percursos experimentados por eles, isto é, sua situação juvenil como objeto de análise em particular é uma marca recente nos estudos acadêmicos como também nas estatísticas resultantes de censos e pesquisas populacionais. No entanto, nas licenciaturas, quando estudantes universitários estão se graduando para trabalhar com adolescentes, esse segmento geracional e suas especificidades se tornam invisíveis.

Nesse sentido, é fundamental distinguir a juventude como momento do desenvolvimento humano que apresenta especificidades, dos jovens como sujeitos que atravessam esse momento. Utilizamos aqui o termo "atravessam", por compreender que o caráter transitório destes grupos etários é marcado por uma característica específica: diferentemente do pertencimento social, sexual ou racial, os sujeitos não pertencem à juventude, eles estão na juventude. Portanto, não são jovens, estão jovens. Como disseram Levi e Schmitt (1996) “... os indivíduos não pertencem a grupos etários, eles os atravessam". 
Além disso, nas relações escolares baseadas na concepção de adolescentes como sujeito em construção, esperança do futuro, futuro cidadão, ele ocupa o lugar do estudante que nada sabe e a quem o adulto construído que tudo sabe, que tudo deve ensinar, transmitirá conhecimento numa prática de educação transmissiva. Essa visão é definidora da relação professor e estudante. Busco Cardoso (2001), que, ao pesquisar as interações comunicativas envolvendo professores e estudantes jovens da classe trabalhadora, diz:

Há um mundo predefinido que orienta o processo comunicativo entre estudantes e professores desconsiderando as possibilidades de intervenção dos educandos. Desconhece-se a importância da linguagem e dos processos relacionais na formação da identidade desses indivíduos." [...] "Ao desconhecer essa importante dimensão da relação comunicativa retira-se a possibilidade de uma educação pautada pela dialogicidade, impedindo que os estudantes coloquem-se como agentes que também constroem e observam o mundo do qual se fala. (p. 21)

\section{Buscando concluir}

O desenho que conseguimos concluir evidenciou a necessidade de que os formadores discutam urgentemente, avaliem e redimensionem as experiências vividas individualmente, pelos coletivos de Departamento, pelos coletivos de Licenciatura e, finalmente, pelos coletivos de Curso, formando-se continuadamente em serviço, também, como profissionais da Educação.

Com efeito, nessa perspectiva, licenciar profissionais para ministrar aulas de Ciências Biológicas, História e Matemática nos quatro últimos anos do EF e no EM, aos sujeitos estudantes adolescentes, pressupõe reconhecê-los - os licenciandos e os adolescentes - como sujeitos que têm vivências e construções próprias e, que, não sendo iguais às dos formadores, não são melhores nem piores. São diferentes! Tal reconhecimento demanda o estudo da realidade geracional, social e histórica, enfim, da realidade cultural desses sujeitos e, para tal, os formadores necessitam formar-se continuadamente e em serviço, habilitar-se a lidar com o outro que, na nossa perspectiva, é um parceiro de seu trabalho. Licenciar-se, enfim, ao magistério na Licenciatura. E como fazê-lo?

Certamente, inexistiu em nossa pesquisa a intenção de propor o ensino da sensibilidade e do respeito ao diferente numa disciplina na Licenciatura, ou mesmo como um tema transversal na Educação Superior. Apenas entendemos que o trato de diferentes situações vividas pelos estudantes do EF e do EM constitui uma das principais características do sujeito que se pretende professor e, portanto, daqueles que se propõem atuar como formadores de 
professores. Os sujeitos que se propõem professores universitários, formadores de professores, habilitadores de licenciandos, precisam demonstrar disposição para se deslocar do lugar do transmitir competência técnica em direção ao lugar do refletir, do construir, do aprender, do educar. E, para tal, entendemos que é fundamental que os formadores se reconheçam sujeitos.

Discutindo, então, sobre a forma mais adequada de orientar a aprendizagem, construir o licenciamento, direcionar a formação de professores que atuarão lidando com adolescentes, cabe, aqui, o questionamento: 0 aprendizado de conteúdos programáticos (componentes curriculares) acrescido de técnicas habilita o professor ao exercício do magistério destinado a adolescentes? Afinal, os documentos oficiais dizem que é para isso que o estudante da Licenciatura está sendo licenciado. Não só o reconhecimento dos professores quanto às dificuldades de tratar com estudantes adolescentes, mesmo na ótica da transmissão de componentes curriculares, apesar de haverem cursado licenciaturas na lógica da racionalidade técnica, como também os dados levantados por nossa pesquisa, autorizam responder negativamente: 0 aprendizado de conteúdos programáticos, acrescido de técnicas, não habilita o professor ao exercício do magistério para adolescentes estudantes, assim como não habilitará o formador ao licenciamento de professores que trabalharão com adolescentes.

Por conseguinte, ao buscar, inicialmente, desvelar a "Sala dos Professores do EF e do EM", nossa pesquisa se embrenhou por um "labirinto" que nos levou à "Sala dos Professores da ES", onde constatamos o isolamento, de maneira bastante similar tanto dos professores quanto dos formadores. Percebemos isso em relatos pessoais ou de pequenos grupos. A inexistência do trabalho coletivo evidenciou-se tanto no caráter pessoal que as disciplinas e seus desenvolvimentos adquirem, quanto no desenrolar do Curso e no desconhecimento de sua totalidade. As falas que se seguem corroboram essa constatação: "Eu sempre fui professor de ..." (Aton). "A cada semestre damos aula de uma disciplina, mas, não fugindo muito da ementa, cada um desenvolve aquilo que acha que deve ser" (Luonnotar), "O resto a gente não sabe [...] Você vai sempre ver professor, como eu, que não tem uma noção geral do Curso, sabe? Mas, pode acreditar" (Tiamat).

Há, ainda, outros depoimentos que reforçam as conclusões de nossa investigação no Mestrado:

Nós não criamos ainda esse, esse espaço de co-responsabilidade nessa formação, sabe? Nem sei se vamos criar. Eu acho que, por vezes, sim, por vezes, não. Mas, desde que a gente consiga oferecer minimamente, uma organização que favoreça, os estudantes mesmo vão fazendo as suas aprendizagens, né, ao longo do tempo. Tá bom?(KUMUSH) 
Entendemos que os formadores de professores, que não enxergam seus estudantes no lugar de sujeitos futuros professores e olvidam os adolescentes no lugar de sujeitos envolvidos diretamente nos objetivos da formação dos licenciandos, assim agem por não assumir, eles próprios, seu lugar de sujeitos. Não se entendem sujeitos das Licenciaturas, embora assumam postura de quem se relaciona com objetos. E, por vezes, ao adotar uma concepção que nega sua prática profissional, o debate, o estudo, a formação continuada e o espaço coletivo na construção das Licenciaturas, acabam por ocupar 0 lugar de objeto.

O fio de Ariadne, que pode conduzir à saída desse labirinto, revertendo o quadro apontado, é a compreensão da necessidade do rompimento com a lógica disciplinar e conteudista existente nas modalidades Licenciatura. Ações como trabalho coletivo, interdisciplinaridade, horário para estudos em grupos, trabalho com projetos, enfim, formação continuada, podem ser o início da construção coletiva da estrutura curricular da Licenciatura. Tais ações devem envolver todos os interessados em cronogramas que prevejam estudos sobre o tema. O objetivo de tais ações seria, de acordo com nossas conclusões, a construção coletiva de uma nova concepção de orientação da aprendizagem que se estruture em função da dinâmica vivenciada no cotidiano da atuação que os professores da EF e EM exercerão como profissionais. O foco da Licenciatura considerará que os profissionais licenciados são os encarregados de orientar a aprendizagem de estudantes adolescentes, em grande maioria, pobres e, por vezes, vivenciando situações que não poderão constituir obstáculos à sua permanência e à permanência com aprendizagem em decorrência de uma deficiência na formação dos licenciados já identificada. Inexiste, aqui, qualquer alusão a reuniões de caráter burocrático para cumprir agenda, em que interesses setoriais são defendidos em detrimento da construção do todo.

Diante do exposto, os elementos coletados nossa pesquisa e a reflexão que fizemos acerca deles autorizam-nos afirmar que é necessário que os formadores das Licenciaturas realizem pesquisas, análises, reflexões, estudos e debates sobre sua atuação como sujeitos, profissionais da Educação, formadores de professores. Partilhamos da concepção de que, para efetivamente colaborar com a humanidade na aquisição da autonomia - autonomia essa adquirida mediante o conhecimento crítico da realidade - a ponto de propiciar a formulação de alternativas, a educação precisa ser concebida, dentro de uma perspectiva que nossa pesquisa vem corroborar qual seja, propiciar ambiente dialógico em que cada sujeito seja reconhecido em sua especificidade e em seu pertencimento ao grupamento humano.

Segundo Vasconcelos (2006:72), quando discute conceitos de educação na obra de Paulo Freire, 
(...) O educador progressista incita no educando a curiosidade sobre os objetos do conhecimento, desafiando-lhe o senso crítico, sabendo ouvir e respeitando seu direito de perguntar, num processo de interação dialógica educador-educando, de tal modo que "quem ensina aprende" e "quem aprende ensina".

\section{Sobre relação dialógica, Freire (2000, p. 118)}

A relação dialógica, porém, não anula, como às vezes se pensa, a possibilidade do ato de ensinar. Pelo contrário, ela funda este ato, que se completa e se sela no outro, o de aprender, e ambos só se tornam verdadeiramente possíveis quando o pensamento crítico, inquieto, do educador ou da educadora não freia a capacidade de criticamente também pensar ou começar a pensar o educando.

Em última análise, um curso que objetiva formar profissionais, orientar a aprendizagem, construir o licenciamento, direcionar a formação de professores para o trabalho com Educação no EF e no EM, de forma que tais profissionais estejam aptos a responder às demandas culturais da função da escola neste início de século, necessita voltar seu olhar para alguns aspectos. Dentre inúmeros outros, salientamos aqueles que a vivência na Sala dos Professores do EF, do EM e da ES nos ensinaram a considerar de fundamental importância e que foram trazidos a nós por um terço dos formadores sujeitos de nossa pesquisa. São eles:

- necessidade de definição de um projeto político-pedagógico para a formação do profissional da ES. Esse projeto deve compreender a formação continuada e em serviço para os formadores das Licenciaturas. Tal projeto, acreditamos, leva em consideração a necessidade de habilitá-los a conduzir processos educativos de construção de conhecimentos que entrelacem as vivências, os interesses, as potencialidades dos estudantes licenciandos com os conteúdos disciplinares;

- necessidade da construção coletiva de um currículo para a Licenciatura que se oriente pela demanda da atuação profissional e não pelo cumprimento de programas desconexos com a realidade. Tal currículo, pensamos, valorizaria a prática investigativa como relevante característica do perfil desejado para os futuros professores e se pautaria no caráter de provisoriedade das certezas científicas. Ao mesmo tempo, contrabalançaria a transposição didática com a aprendizagem dos conteúdos, incentivando o diálogo entre a produção contínua do conhecimento e a sua ressignificação no contexto escolar. A apresentação dele para posterior discussão de ementas, programas, objetivos e relevância das disciplinas na formação dos licenciandos seria parte constitutiva da construção deste currículo; 
- necessidade de construção coletiva de uma organização institucional que se subordine à proposta pedagógica, porque ela própria tem papel formador. Tal organização institucional, na nossa perspectiva, viabilizaria tempo e espaço coletivos para discussões, leituras, pesquisas, estudos, socializações de vivências, reflexões das práticas, participação efetiva no cotidiano administrativo da Universidade, discussões de algumas relações (formadores e licenciandos, universidade e sociedade, sistemas educacionais), apresentação de pesquisas desenvolvidas e em andamento que, pautados na análise da prática, constituam o fundamento da construção teórica;

- necessidade de um levantamento - no máximo no segundo semestre do Curso - e conseqüente estudo do perfil dos estudantes da Licenciatura visando à adequação de planejamento e de ações pedagógicas necessárias. Tal planejamento incluiria, se necessário, a formação continuada dos formadores quanto ao estudo e aprofundamento de alternativas pedagógicas, pedagogia de projetos, interdisciplinaridade, transdisciplinaridade, gestão democrática, projeto político-pedagógico, ciclos do desenvolvimento humano, tempos escolares, educação inclusiva, (re)significação curricular, juventudes, entre outros. As ações pedagógicas incluiriam estratégias de supressão de eventuais deficiências que os licenciandos carreguem consigo da escolarização básica, bem como momentos de retorno de ex-estudantes para avaliar a adequação do currículo oferecido à demanda da realidade das escolas de EF e de EM. Isso porque essas deficiências eles vivenciam, agora, em suas práticas docentes.

Por fim, parece-nos importante destacar que nossa pesquisa não objetivou culpabilizar os formadores identificando-os como causadores dos problemas da formação inicial dos professores do EF e do EM. O objetivo, aqui, foi apontar algumas possibilidades de ação que os formadores têm mesmo sendo vitimados pelo esquema de roda viva imposto pelo sistema econômico vigente e, portanto, podendo apontar alternativas para parte dos desafios. Frisamos também que nossa contribuição se destina a todos os formadores independentemente de Curso, de Área do Conhecimento ou de instituição da Educação Superior. Como já foi dito, trabalhamos com a idéia de melhoria das condições objetivas, na esfera pedagógica, de orientar a aprendizagem, de construir 0 licenciamento.

Por fim, merecem destaque algumas iniciativas - poucas, porém brilhantes - de alguns dos formadores participantes de nossa pesquisa que, por já se entenderem sujeitos, incorporam as suas vivências educacionais e crenças pessoais às práticas educativas que optaram por desenvolver. 


\section{Referências}

CARDOSO, Ércio do Carmo Sena. Interações Comunicativas em uma escola noturna: a construção do lugar na fala de seus sujeitos, 2001. Dissertação (Mestrado) - Universidade Federal de Minas Gerais, Faculdade de Filosofia e Ciências Humanas, Minas Gerais, 2001.

FREIRE, Paulo. Pedagogia da esperança. 7. ed. Rio de Janeiro: Paz e Terra, 2000 .

MELUCCI, Alberto. Juventude, tempo e movimentos sociais. In: Juventude e Contemporaneidade. Revista Brasileira de Educação. São Paulo, n.5-6, (número especial), 1997.

Da SILVA, Analise de Jesus. Relações entre formadores, professores e adolescentes: de objetos no Labirinto a sujeitos da Educação, 2002. Dissertação (Mestrado) - Universidade Federal de Minas Gerais, Faculdade de Educação, Belo Horizonte, 2002.

VASCONCELOS, Maria Lúcia Marcondes Carvalho; BRITO, Regina Helena Pires de. Conceitos de educação em Paulo Freire. Petrópolis: Vozes, 2006.

WILKINSON, Philip. 0 livro ilustrado da mitologia: lendas e histórias fabulosas sobre os grandes heróis e deuses do mundo inteiro. São Paulo: Publifolha, 2000.

LEVI, Giovanni; SCHMTT, Jean-Claude (Orgs.). História dos Jovens 1: da Antiguidade à Era Moderna. São Paulo: Companhia das Letras, 1996. 


\section{Anexo 1}

\section{Tabela 1. Relação entre disciplinas específicas da licenciatura e disciplinas comuns ao bacharelado na ufmg - 2005}

\begin{tabular}{|lllclc|}
\hline Curso & Turno & $\begin{array}{l}\text { N.o de } \\
\text { Disciplinas } \\
\text { Específicas da } \\
\text { Formação }\end{array}$ & \% & $\begin{array}{l}\text { No de } \\
\text { Disciplinas } \\
\text { Comuns ao } \\
\text { Bacharelado }\end{array}$ & \% \\
\hline Ciências & Diumo & 20 & 13 & 129 & 87 \\
Biológicas & Noturno & 15 & 11 & 119 & 89 \\
\hline Histónia & Diumo & 05 & 09 & 053 & 91 \\
& Noturno & 05 & 8,5 & 054 & 91,5 \\
\hline Matemática & Diumo & 14 & 21 & 053 & 79 \\
& Noturno & 13 & 25 & 040 & 75 \\
\hline
\end{tabular}

Recebido: 05 de dezembro de 2006 Aprovado: 12 de fevereiro de 2007 